\title{
Status pemberian ASI terhadap status gizi bayi usia 6-12 bulan
}

\section{Breastfeeding status on nutritional status of infants aged 6-12 months}

Normayanti ${ }^{1}$, Nila Susanti ${ }^{2}$

\begin{abstract}
Background: Coverage of exclusive breastfeeding in Indonesia fluctuate and showed a declining trend over the last three years. Coverage of exclusive breastfeeding of Palangka Raya city is still very low at around $23.30 \%$. There are several variables suspected as the cause of the malnutrition problem, the variables are status of breastfeeding, mother's education level, mother's employment, mother's knowledge of nutrition and counseling status of breastfeeding.

Objective: This study aimed to determine the effect of breastfeeding status on the nutritional status of infants aged 6-12 months in the working area of UPTD Puskesmas Kalampangan Palangka Raya city.

Method: The study design used was a case-control with 1:2 ratio, the case are infants aged 6-12 months with low nutritional status, whereas the comparison are infants aged 6-12 months with normal nutritional status. The dependent variable is the nutritional status and the independent variables are breastfeeding status, mother's education level, mother's employment, mother's knowledge of nutrition, and breastfeeding counseling status. Data analysis was performed by univariate, bivariate (Chi-Square) and multivariate (logistic regression).

Results: From the 5 (five) variables were analyzed, 2 (two) variables independently became risk factor for malnutrition are status of breastfeeding $(O R=6.667)$ and the counseling status of breastfeeding $(O R=3.215)$. But together (simultaneously), only breastfeeding status has an influence on the nutritional status of infants, and non-exclusive breastfeeding was significant as a risk factor for malnutrition $(O R=5.126)$. Probability infant to experience malnutrition due to breastfeeding status no exclusive is at $25.54 \%$.

Conclusion: Breastfeeding status has an influence on the nutritional status of infants and non-exclusive breastfeeding was significant as a risk factor for malnutrition among infants aged 6-12 months.
\end{abstract}

KEY WORDS: breastfeeding status, nutritional status, infant, case-control

\begin{abstract}
ABSTRAK
Latar belakang: Cakupan pemberian ASI eksklusif di Indonesia berfluktuasi dan menunjukkan kecenderungan menurun selama tiga tahun terakhir. Cakupan pemberian ASI eksklusif di Kota Palangka Raya masih sangat rendah yaitu sekitar 23,30\%. Ada beberapa variabel yang diduga menjadi penyebab masalah gizi kurang pada bayi yaitu status pemberian ASI, tingkat pendidikan ibu, pekerjaan ibu, pengetahuan gizi ibu, dan status konseling ASI.

Tujuan: Mengetahui pengaruh status pemberian ASI terhadap status gizi bayi usia 6-12 bulan di wilayah kerja UPTD Puskesmas Kalampangan Kota Palangka Raya.

Metode: Rancangan penelitian ini adalah kasus-kontrol dengan perbandingan 1:2. Kasus adalah bayi usia 6-12 bulan dengan status gizi kurang sedangkan pembanding adalah bayi usia 6-12 bulan dengan status gizi normal. Variabel terikat adalah status gizi sedangkan variabel bebas yaitu status pemberian ASI, tingkat pendidikan ibu, pekerjaan ibu, pengetahuan gizi ibu, dan status konseling ASI. Analisis data dilakukan secara univariat, bivariat (Chi-Square), dan multivariat (regresi logistik).

Hasil: Dari 5 (lima) variabel yang dianalisis, 2 (dua) variabel merupakan faktor risiko terjadinya gizi kurang yaitu status pemberian ASI $(O R=6,667)$ dan status konseling ASI $(O R=3,215)$. Namun, secara simultan hanya status pemberian ASI yang memiliki pengaruh terhadap status gizi bayi dan ASI tidak eksklusif merupakan faktor risiko gizi kurang $(\mathrm{OR}=5,126)$. Probabilitas bayi untuk mengalami gizi kurang karena status pemberian ASI yang tidak eksklusif adalah sebesar $25,54 \%$.

Simpulan: Status pemberian ASI berpengaruh terhadap status gizi bayi dan ASI tidak eksklusif merupakan faktor risiko gizi kurang pada bayi usia 6-12 bulan.
\end{abstract}

KATA KUNCI: status pemberian ASI, status gizi, bayi, kasus kontrol

\section{PENDAHULUAN}

Status gizi masyarakat dipengaruhi oleh banyak faktor yang kompleks dan saling berhubungan satu sama lain. Pada tingkat rumah tangga, status gizi dipengaruhi oleh kemampuan rumah tangga untuk menyediakan makanan yang cukup, baik dari segi kualitas maupun kuantitasnya (1). Zat gizi memiliki peranan yang sangat

\footnotetext{
Korespondensi: Unit Pelaksana Teknis Daerah Puskesmas Kalampangan Kota Palangka Raya, Jl. Mahir Mahar Km 18,5, Palangka Raya, e-mail: gizi_kalampangan@yahoo.co.id

2 Jurusan Gizi Politeknik Kesehatan Kementerian Kesehatan Palangka Raya, Jl. George obos No.30, Palangka Raya, e-mail: nilafado_gk@ yahoo.co.id
} 
penting bagi kelangsungan tumbuh kembang anak dan kesehatannya. Sumber zat gizi yang terbaik untuk bayi di kehidupan pertamanya adalah air susu ibu (ASI). Air susu ibu merupakan satu-satunya makanan terbaik bagi bayi karena mengandung komposisi gizi yang paling lengkap dan ideal untuk pertumbuhan dan perkembangan bayi. Jumlah ASI yang dikonsumsi termasuk energi dan zat gizi lainnya yang terkandung di dalam ASI sangat menentukan pertumbuhan dan perkembangan bayi (2).

Pemberian ASI berpengaruh positif terhadap kesehatan dan status gizi anak. Sebuah meta-analisis di negara berkembang menunjukkan bahwa bayi yang tidak diberikan ASI memiliki risiko enam kali lipat lebih besar mengalami kematian akibat penyakit infeksi dalam dua bulan pertama kehidupan dibandingkan dengan bayi yang diberikan ASI (3). United Nations Emergency Children's Fund (UNICEF) bersama World Health Assembly (WHA) dan banyak negara lainnya menetapkan jangka waktu pemberian ASI eksklusif selama 6 bulan dimulai sejak bayi lahir. World Health Organization (WHO) telah mengkaji lebih dari 3000 penelitian yang menunjukkan pemberian ASI selama 6 bulan adalah jangka waktu yang paling optimal untuk pemberian ASI eksklusif. Hal ini berdasarkan bukti ilmiah bahwa ASI eksklusif mencukupi kebutuhan gizi bayi sehingga pertumbuhan bayi menjadi lebih baik (4).

Hasil penelitian di Bogor menunjukkan bahwa anak yang diberi ASI saja sampai usia 4 bulan, tidak ada yang menderita gizi buruk ketika mereka berusia 5 bulan. Proporsi pemberian ASI pada bayi kelompok usia 0 bulan sebesar $73,1 \%$, 1 bulan $55,5 \%$, 2 bulan $43 \%$, 3 bulan $36 \%$, dan kelompok usia 4 bulan 16,7\%. Pada usia bayi yang semakin bertambah, terjadi penurunan pola pemberian ASI sebesar 1,3 kali atau sebesar 77,2\%. Anak-anak yang tidak diberi ASI eksklusif juga lebih cepat terjangkit penyakit kronis seperti kanker, jantung, hipertensi, dan diabetes setelah dewasa. Kemungkinan anak menderita kekurangan gizi dan obesitas juga lebih besar (5).

Provinsi Kalimantan Tengah menempati peringkat tertinggi ke-4 secara nasional dengan jumlah anak gizi kurang sebesar $22,3 \%$ dan gizi buruk sebesar $5,3 \%$ menurut indeks berat badan menurut umur (BB/U) (6). Prevalensi gizi kurang pada balita di Kota Palangka Raya yaitu sekitar $20 \%$ sedangkan untuk wilayah kerja Puskesmas Kalampangan mencapai 18\% (7). Cakupan pemberian ASI eksklusif di Indonesia berfluktuasi dan menunjukkan kecenderungan menurun selama tiga tahun terakhir. Cakupan pemberian ASI eksklusif bayi usia 0-6 bulan secara nasional (target nasional $80 \%$ ) pada tahun 2010 adalah sekitar 15,3\%. Cakupan ASI eksklusif di Kota Palangka Raya juga masih rendah yaitu sekitar 23,30\% bahkan untuk wilayah kerja Puskesmas Kalampangan hanya mencapai 5,76\%. Penurunan cakupan ASI eksklusif simultan dengan meningkatnya prevalensi gizi kurang pada anak (8).
Berdasarkan latar belakang tersebut, peneliti tertarik untuk melakukan penelitian lebih lanjut mengenai status pemberian ASI eksklusif atau tidak eksklusif terhadap status gizi bayi. Tujuan penelitian ini adalah untuk mengetahui pengaruh status pemberian ASI terhadap status gizi bayi usia 6-12 bulan.

\section{BAHAN DAN METODE}

Penelitian ini merupakan penelitian case control yang dilaksanakan pada bulan Juli 2012 - Januari 2013 di wilayah kerja Unit Pelaksana Teknis Daerah (UPTD) Puskesmas Kalampangan Kota Palangka Raya yang mencakup 4 (empat) kelurahan yaitu Kelurahan Kalampangan, Kelurahan Bereng Bengkel, Kelurahan Kameloh Baru, dan Kelurahan Danau Tunday. Populasi penelitian adalah semua bayi yang berusia 6-12 bulan yang ada di wilayah kerja UPTD Puskesmas Kalampangan. Sampel kasus penelitian adalah seluruh bayi dengan status gizi kurang yang ditemukan di wilayah penelitian sedangkan untuk sampel kontrol dipilih dengan metode simple random sampling (pengambilan sampel secara acak dan sederhana) dan memenuhi kriteria inklusi dan eksklusi.

Kriteria inklusi sampel kasus adalah bayi usia 6-12 bulan dengan status gizi kurang (z-score antara -3,00 SD sampai dengan -2,00 SD WHO antropometri 2005) berdasarkan indeks berat badan menurut umur (BB/U) sedangkan sampel kontrol adalah bayi usia 6-12 bulan dengan kategori status gizi normal (z-score -2,00 SD sampai dengan +1,00 SD WHO antropometri 2005); bertempat tinggal di wilayah kerja UPTD Puskesmas Kalampangan Kota Palangka Raya; lahir dengan berat badan normal ( $\geq 2,5 \mathrm{~kg}$ ); dan ibu dari bayi bersedia menjadi sampel penelitian dengan mengisi informed consent. Kriteria eksklusi subjek penelitian ini adalah subjek pernah menderita penyakit infeksi dalam 3 bulan terakhir.

Besar sampel dihitung berdasarkan rumus dengan derajat kepercayaan $\left(Z_{1-\alpha / 2}\right) 95 \%$; kekuatan uji $\left(Z_{1-\beta}\right)$ sebesar 0,842 ; estimasi proporsi pada kelompok kasus (P1) sebesar 0,75 ; dan estimasi proporsi pada kelompok kontrol (P2) sebesar 0,35 sehingga diperoleh sampel minimal pada masing-masing kelompok sebesar 23 orang. Dalam penelitian ini terdapat keterbatasan jumlah sampel untuk analisis multivariat. Keterbatasan ini diatasi dengan cara mengambil sampel kontrol sebanyak 46 bayi usia 6-12 bulan dengan status gizi normal sehingga diperoleh perbandingan antara kasus dan kontrol sebesar 1:2 dengan total subjek dalam penelitian adalah 69 bayi usia 6-12 bulan. Data yang digunakan merupakan data primer yang langsung diperoleh dari responden dengan wawancara langsung kepada ibu. Data primer meliputi umur, berat badan, status gizi bayi, status pemberian ASI (ASI eksklusif atau tidak), tingkat pendidikan ibu 
dengan kriteria pendidikan dasar (SD/sederajat dan SMP/ sederajat) dan pendidikan lanjut (SMA/sederajat, akademi atau perguruan tinggi), pekerjaan ibu, pengetahuan gizi ibu, dan status konseling ASI.

ASI eksklusif adalah bayi hanya disusui atau diberi ASI saja; sejak lahir bayi belum diberi makanan atau minuman selain ASI sampai sebelum usia 6 bulan; dan sebelum ASI keluar bayi tidak diberi makanan prelakteal berupa makanan atau minuman lain, termasuk air putih, selain menyusui (kecuali obat-obatan dan vitamin atau mineral tetes; ASI perah juga diperbolehkan) (9). Usia bayi 6-12 bulan dipilih karena bayi dapat dikatakan menerima ASI eksklusif jika pemberian ASI telah sesuai dengan persyaratan ASI eksklusif yaitu mencapai usia 6 (enam) bulan .

Pengetahuan gizi ibu antara lain mengenai pengetahuan tentang ASI (pengertian dan manfaat), kolostrum (pengertian, ciri-ciri, dan manfaat), praktik pemberian ASI (teknik menyusui, lamanya menyusui, pemberian ASI), dan kesehatan bayi yang diperoleh melalui pengalaman, membaca buku, dan informasi dari orang lain. Pengetahuan gizi ibu diukur menggunakan kuesioner dengan kriteria kurang jika skor kurang dari $75 \%$ dari total skor dan baik jika skor lebih dari atau sama dengan $75 \%$ dari total skor.

Status konseling ASI dibedakan menjadi dua kriteria yaitu tidak mendapatkan konseling ASI dan mendapatkan konseling ASI. Konseling ASI dilakukan selama 30-45 menit dengan materi yang mencakup praktik menyusui (manfaat dan kegunaan ASI bagi bayi), proses menyusui (teknik dan riwayat menyusui), dan minimal 1 kali pada saat pranatal, perinatal ataupun postnatal - ibu melakukan antenatal care (ANC). Konseling dilakukan oleh petugas kesehatan (dokter dan dokter spesialis, bidan, perawat, ahli gizi, dan tenaga kesehatan lainnya) yang telah mendapatkan pelatihan tentang konseling ASI atau menyusui.

Analisis bivariat menggunakan uji statistik Chi-Square $\left(\mathrm{X}^{2}\right)$ dan analisis multivariat menggunakan uji regresi logistik dengan tingkat kemaknaan ( $p$ ) kurang dari 0,05. Apabila pada uji bivariat tidak menunjukkan adanya hubungan yang bermakna antara variabel bebas dengan variabel terikat, syarat nilai $p$ kurang dari 0,25 tidak terpenuhi, dan adanya multikolinearitas antar variabel pada uji multivariat maka variabel bebas tersebut tidak dimasukkan ke dalam analisis multivariat. Analisis data menggunakan program software SPSS version 19 for windows.

\section{HASIL}

\section{Karakteristik subjek penelitian}

Sebagian besar subjek $(36,2 \%)$ pada kelompok kasus dan kontrol yang mengikuti penelitian ini berumur 6 bulan. Menurut jenis kelamin, pada kelompok kasus maupun kontrol sebagian besar adalah perempuan $(52,2 \%$ dan $54,3 \%)$. Karakteristik distribusi umur ibu
Tabel 1. Karakteristik subjek penelitian

\begin{tabular}{lcccc}
\hline & \multicolumn{5}{c}{ Kelompok } \\
\cline { 2 - 6 } & \multicolumn{3}{c}{ Kasus } & \multicolumn{3}{c}{ Kontrol } \\
\cline { 2 - 6 } & $\mathbf{n}$ & $\%$ & $\mathbf{n}$ & $\%$ \\
\hline $\begin{array}{l}\text { Jenis kelamin } \\
\quad \text { Laki-laki }\end{array}$ & 11 & 47,8 & 21 & 45,7 \\
$\quad$ Perempuan & 12 & 52,2 & 25 & 54,3 \\
Tingkat pendidikan ibu & & & & \\
$\quad$ Pendidikan dasar & 18 & 78,3 & 25 & 54,3 \\
$\quad$ Pendidikan lanjut & 5 & 21,7 & 21 & 45,7 \\
Pekerjaan ibu & & & & \\
$\quad$ Bekerja & 1 & 4,3 & 2 & 4,3 \\
$\quad$ Tidak bekerja & 22 & 95,7 & 44 & 95,7 \\
Status pemberian ASI & & & & \\
$\quad$ Tidak ASI eksklusif & 20 & 87,0 & 23 & 50,0 \\
$\quad$ ASI eksklusif & 3 & 13,0 & 23 & 50,0 \\
Pengetahuan gizi ibu & & & & \\
$\quad$ Kurang & 11 & 47,8 & 19 & 41,3 \\
$\quad$ Baik & 12 & 52,2 & 27 & 58,7 \\
Status konseling ASI & 14 & 60,9 & 15 & 32,6 \\
$\quad$ Tidak mendapatkan konseling ASI \\
$\quad$ Mendapatkan konseling ASI & 9 & 39,1 & 31 & 67,4 \\
\hline
\end{tabular}

sebagian besar berada dalam rentang umur $22-26$ tahun $(30,4 \%)$ dan $27-31$ tahun (31,9\%). Pada Tabel 1 terlihat bahwa persentase kelompok kasus sebagian besar menunjukkan status pemberian ASI tidak eksklusif $(87,0 \%)$, tingkat pendidikan dasar $(78,3 \%)$, tidak bekerja $(95,7 \%)$, pengetahuan gizi ibu baik $(52,2 \%)$, dan ibu bayi tidak mendapatkan konseling ASI (60,9\%). Berdasarkan status pemberian ASI eksklusif, proporsi yang lebih besar ditemukan pada kelompok kontrol $(50,0 \%)$.

Hasil analisis dengan uji Chi Square menunjukkan bahwa terdapat hubungan yang bermakna antara status pemberian ASI dengan status gizi bayi $(p<0,05)$ dan pemberian ASI tidak eksklusif merupakan faktor risiko terjadinya gizi kurang (OR=6,667; 95\% Cl:1,738-5,565). Odds ratio (OR) hasil uji bivariat menunjukkan bahwa bayi yang tidak mendapatkan ASI eksklusif memiliki risiko 6,667 kali lebih besar untuk mengalami status gizi kurang dibandingkan dengan yang mendapatkan ASI eksklusif (Tabel 2). Analisis juga menunjukkan adanya hubungan yang bermakna antara status konseling ASI dengan status gizi bayi $(p<0,05)$ yaitu ibu yang tidak mendapat konseling ASI merupakan faktor risiko terjadinya gizi kurang (OR=3,215; 95\% Cl:1,136-9,094).

Pada Tabel 3 dapat diketahui bahwa hasil analisis multivariat dengan menggunakan regresi logistik menunjukkan terdapat pengaruh yang bermakna variabel status pemberian ASI terhadap variabel status gizi bayi ( $p=0,029$; OR=5,126; 95\% Cl:1,177-22,321). Nilai Odds Ratio (OR) hasil analisis multivariat sebesar 5,126 menunjukkan bahwa bayi yang tidak mendapatkan ASI eksklusif memiliki risiko 5,126 kali lebih besar untuk mengalami status gizi kurang dibandingkan dengan bayi yang mendapatkan ASI secara eksklusif. 
Tabel 2. Analisis bivariat berbagai variabel yang berhubungan dengan status gizi bayi

\begin{tabular}{|c|c|c|c|c|c|c|c|}
\hline \multirow{3}{*}{ Variabel } & \multicolumn{4}{|c|}{ Kelompok } & \multirow{3}{*}{$X^{2}$} & \multirow{3}{*}{ p } & \multirow{3}{*}{$\begin{array}{c}\text { OR } \\
(95 \% \mathrm{Cl})\end{array}$} \\
\hline & \multicolumn{2}{|c|}{ Kasus } & \multicolumn{2}{|c|}{ Kontrol } & & & \\
\hline & $\mathbf{n}$ & $\%$ & $\mathbf{n}$ & $\%$ & & & \\
\hline $\begin{array}{l}\text { Status pemberian ASI } \\
\text { Tidak ASI eksklusif } \\
\text { ASI eksklusif }\end{array}$ & $\begin{array}{c}20 \\
3\end{array}$ & $\begin{array}{l}87,0 \\
13,0\end{array}$ & $\begin{array}{l}23 \\
23\end{array}$ & $\begin{array}{l}50,0 \\
50,0\end{array}$ & 8,918 & $0,003^{*}$ & $\begin{array}{c}6,667 \\
(1,738-5,565)\end{array}$ \\
\hline $\begin{array}{l}\text { Tingkat pendidikan ibu } \\
\text { Pendidikan dasar } \\
\text { Pendidikan lanjut }\end{array}$ & $\begin{array}{c}18 \\
5\end{array}$ & $\begin{array}{l}78,3 \\
21,7\end{array}$ & $\begin{array}{l}25 \\
21\end{array}$ & $\begin{array}{l}54,3 \\
45,7\end{array}$ & 3,734 & 0,053 & $\begin{array}{c}3,024 \\
(0,959-9,533)\end{array}$ \\
\hline $\begin{array}{l}\text { Pekerjaan ibu } \\
\text { Tidak bekerja } \\
\text { Bekerja }\end{array}$ & $\begin{array}{c}22 \\
1\end{array}$ & $\begin{array}{c}95,7 \\
4,3\end{array}$ & $\begin{array}{c}44 \\
2\end{array}$ & $\begin{array}{c}95,7 \\
4,3\end{array}$ & 0,000 & 1,000 & $\begin{array}{c}1,000 \\
(0,086-1,640)\end{array}$ \\
\hline $\begin{array}{l}\text { Pengetahuan gizi ibu } \\
\text { Kurang } \\
\text { Baik }\end{array}$ & $\begin{array}{l}11 \\
12\end{array}$ & $\begin{array}{l}47,8 \\
52,2\end{array}$ & $\begin{array}{l}19 \\
27\end{array}$ & $\begin{array}{l}41,3 \\
58,7\end{array}$ & 0,265 & 0,606 & $\begin{array}{c}1,303 \\
(0,476-3,565)\end{array}$ \\
\hline $\begin{array}{l}\text { Status konseling ASI } \\
\text { Tidak } \\
\text { Ya }\end{array}$ & $\begin{array}{c}14 \\
9\end{array}$ & $\begin{array}{l}60,9 \\
39,1\end{array}$ & $\begin{array}{l}15 \\
31\end{array}$ & $\begin{array}{l}32,6 \\
67,4\end{array}$ & 5,026 & $0,025^{*}$ & $\begin{array}{c}3,215 \\
(1,136-9,094)\end{array}$ \\
\hline
\end{tabular}

Keterangan: * bermakna $(p<0,05)$

Tabel 3. Analisis multivariat regresi logistik pengaruh status pemberian ASI, tingkat pendidikan ibu, dan status konseling ASI terhadap status gizi bayi usia 6-12 bulan

\begin{tabular}{lcccc}
\hline \multicolumn{1}{c}{ Variabel } & Koef B & S.E (B) & p & OR (95\% Cl) \\
\hline $\begin{array}{l}\text { Status pemberian ASI } \\
\quad \text { Tidak ASI eksklusif }\end{array}$ & 1,634 & 0,751 & 0,029 & $5,126(1,177-2,321)$ \\
$\begin{array}{c}\text { Tingkat pendidikan Ibu } \\
\quad \text { Pendidikan dasar }\end{array}$ & 0,963 & 0,624 & 0,123 & $2,618(0,771-8,891)$ \\
$\begin{array}{l}\text { Status konseling ASI } \\
\quad \text { Tidak mendapatkan konseling ASI }\end{array}$ & 0,437 & 0,767 & 0,473 & $1,548(0,469-5,108)$ \\
\hline
\end{tabular}

\section{BAHASAN}

Hasil penelitian ini menunjukkan bahwa pemberian ASI eksklusif berhubungan bermakna dengan status gizi balita usia 6-12 bulan. Hal ini sejalan dengan hasil penelitian di Sulawesi Selatan pada balita usia 6-59 bulan (10). Demikian pula penelitian sebelumnya yang menyatakan adanya hubungan antara pemberian ASI eksklusif dengan status gizi anak usia 4-11 bulan, baik di wilayah pedesaan maupun perkotaan di Kabupaten Temanggung (11).

Pada penelitian ini, proporsi status pemberian ASI tidak eksklusif pada kelompok kasus sebanyak $87,0 \%$. Hal ini menunjukkan bahwa sebagian besar kelompok bayi dengan gizi kurang adalah bayi yang tidak diberikan ASI eksklusif oleh ibunya. Hasil analisis bivariat menunjukkan bahwa bayi yang tidak mendapatkan ASI eksklusif memiliki risiko yang lebih besar untuk mengalami status gizi kurang dibandingkan dengan yang mendapatkan ASI eksklusif sehingga rendahnya pemberian ASI eksklusif merupakan hal penting yang harus diatasi dalam upaya pencegahan terjadinya gizi kurang.

Selain itu, analisis multivariat juga menunjukkan bahwa status pemberian ASI merupakan faktor yang paling dominan berpengaruh terhadap status gizi bayi dan tidak mendapatkan ASI eksklusif menunjukkan risiko terjadinya gizi kurang pada bayi. Hasil ini mendukung pentingnya gerakan menyusui secara eksklusif untuk menjadi langkah intervensi yang dapat menyelamatkan dan memberikan perlindungan terbaik bagi bayi di awal kehidupannya. Analisis dampak berupa atributtable risk (AR) pada penelitian kasus kontrol di Nusa Tenggara Barat juga menunjukkan hasil bahwa sebanyak $28,57 \%$ bayi usia 6-12 bulan dapat terhindar dari menderita gizi kurang jika mendapatkan ASI secara eksklusif (12).

ASI merupakan makanan utama bagi bayi sampai berusia 6 (enam) bulan. ASI mengandung berbagai zat gizi yang lengkap dalam jumlah sesuai kebutuhan (13). Di samping itu, ASI juga mengandung berbagai zat antibodi yang sangat diperlukan bayi atau anak untuk pertahanan tubuh dari berbagai penyakit infeksi. Sebelum usia 6 (enam) bulan, anak tidak perlu diberikan makanan atau minuman apapun karena kebutuhan gizi bayi dapat terpenuhi dari ASI. Sebelum usia 6 (enam) bulan, sistem pencernaan bayi belum dapat mencerna makanan atau minuman selain ASI sehingga jika dipaksakan maka bayi berpotensi menderita infeksi terutama pada sistem pencernaan. Anak-anak yang mengalami infeksi sangat mudah mengalami penurunan status gizi (14). Pemberian 
ASI eksklusif dapat meningkatkan kelangsungan hidup bayi karena dapat menurunkan angka kematian bayi sebesar $13 \%$ sehingga perencanaan kesehatan harus lebih memperhatikan tentang promosi ASI eksklusif (15).

Berdasarkan tingkat pendidikan, sebagian besar kasus $(78,3 \%)$ memiliki ibu dengan tingkat pendidikan dasar. Proporsi tersebut lebih tinggi jika dibandingkan dengan kelompok kontrol (54,3\%). Sebaliknya, untuk tingkat pendidikan lanjut, proporsi lebih besar ditemukan pada kelompok kontrol $(45,7 \%)$. Hasil analisis menunjukkan tingkat pendidikan ibu tidak berhubungan bermakna dengan status gizi bayi. Hasil penelitian ini sesuai dengan penelitian di Semarang yang menunjukkan tidak adanya hubungan antara tingkat pendidikan ibu dengan status gizi balita. Gizi kurang bisa terjadi pada balita dengan tingkat pendidikan ibu yang tinggi dan sebaliknya gizi baik bisa terjadi pada balita dengan tingkat pendidikan ibu yang rendah. Perbedaan dengan teori yang ada dapat disebabkan oleh pola asuh ibu dan keluarga terhadap balita atau dipengaruhi faktor lain seperti jumlah anggota keluarga, pendapatan keluarga, dan lain-lain (16).

Proporsi ibu bayi yang bekerja pada kelompok kasus sebesar 4,3\% menunjukkan bahwa hanya sebagian kecil kasus memiliki ibu yang bekerja, proporsi ini sama besarnya dengan kelompok kontrol. Hasil analisis menunjukkan bahwa tidak terdapat hubungan yang bermakna antara pekerjaan ibu dengan status gizi bayi. Hal ini sejalan dengan penelitian di Banten yang menyatakan bahwa tidak terdapat hubungan bermakna antara pekerjaan ibu dengan status gizi anak (17). Status pekerjaan ibu digunakan untuk mengetahui penggunaan waktu sehari-hari ibu untuk bayi sehingga dengan mengetahui status pekerjaannya (ibu bekerja atau tidak bekerja) dapat dijadikan dasar penentuan perilaku dan sikap ibu tersebut. Ibu yang tidak bekerja akan mempunyai waktu yang lebih banyak untuk mengurus keluarganya, terutama bayinya. Terlepas dari itu, sebenarnya khusus untuk ibu yang bekerja dan mempunyai bayi yang harus diberi ASI, telah dibuat suatu aturan tertentu agar dapat memberikan ASI secara eksklusif kepada bayinya walaupun ibu masih bekerja. Salah satunya adalah dengan memberikan ASI perah yang telah ibu sediakan sehingga kebutuhan zat gizi dapat terus terpenuhi sesuai kebutuhan bayi untuk pertumbuhan dan perkembangannya. Aturan tersebut termuat dalam peraturan bersama Menteri Negara Pemberdayaan Perempuan No.48/MEN.PP/ XII/2008, Menteri Tenaga Kerja dan Transmigrasi PER. 27/MEN/XII/2008, dan Menteri Kesehatan 1177/MENKES/ $\mathrm{PB} / \mathrm{XII} / 2008$ tentang peningkatan pemberian air susu ibu selama waktu kerja di tempat kerja (18).

Proporsi ibu dengan pengetahuan gizi kurang pada kelompok kasus sebesar $47,8 \%$. Hal ini menunjukkan bahwa lebih banyak ibu yang memiliki pengetahuan gizi baik. Demikian pula pada kelompok kontrol, proporsi pengetahuan gizi baik ditemukan lebih tinggi $(58,7 \%)$.
Penelitian ini menunjukkan bahwa tidak terdapat hubungan yang bermakna antara pengetahuan gizi ibu dengan status gizi balita, hal ini sejalan dengan teori yang menyatakan bahwa terbentuknya suatu perilaku baru terutama pada orang dewasa dimulai dari aspek kognitif, dalam arti subjek tahu terlebih dahulu terhadap stimulus yang berupa materi sehingga menimbulkan pengetahuan baru pada subjek tersebut. Pengetahuan atau kognitif merupakan domain yang sangat penting bagi terbentuknya tindakan seseorang karena perilaku yang didasari pengetahuan akan bersifat lebih langgeng daripada perilaku yang tidak didasari pengetahuan yang baik. Contoh perilaku yang sangat berpengaruh seperti misalnya perilaku dalam memberikan asupan gizi kepada balita (19). Pengetahuan merupakan salah satu penyebab gizi kurang, tetapi kemiskinan dan kekurangan persediaan pangan yang bergizi juga merupakan faktor penting dalam masalah gizi kurang (20).

Proporsi ibu yang tidak mendapatkan konseling ASI pada kelompok kasus sebanyak $60,9 \%$ sedangkan untuk ibu yang mendapatkan konseling ASI, proporsi lebih besar ditemukan pada kelompok kontrol $(67,4 \%)$. Hasil penelitian ini sejalan dengan hasil penelitian di Ghana yang menyatakan bahwa kegiatan konseling laktasi dan pelatihan konseling ASI bagi ibu dapat meningkatkan pemberian ASI eksklusif pada bayi serta meningkatkan kecerdasan dan pertumbuhan fisik anak (21). Demikian pula menurut penelitian yang dilakukan di Brazil yang menyatakan bahwa konseling laktasi dapat mencegah penghentian menyusui dini dan efektif dalam meningkatkan pemberian ASI eksklusif termasuk durasi ASI (22).

Namun, analisis multivariat menunjukkan bahwa secara statistik tidak terdapat pengaruh yang bermakna antara konseling ASI terhadap status gizi. Meski demikian, hasil penelitian di Bangladesh menunjukkan bahwa ibu dengan persepsi yang benar tentang kesehatan bayi dan menyusui secara eksklusif, lebih menyadari pentingnya menjaga kesehatan bayi dan mempraktikkan ASI eksklusif dibandingkan ibu menyusui lainnya yang belum memiliki anggapan yang benar tentang ASI eksklusif (23). Ibu mulai memberikan ASI segera setelah bayi lahir tetapi juga seringkali mulai memberikan makanan pendamping-ASI (MP-ASI) yang terlalu dini atau berhenti menyusui dalam waktu beberapa minggu setelah melahirkan.

Penelitian di Swedia menunjukkan bahwa petugas kesehatan yang melakukan konseling untuk mendukung pemberian $\mathrm{ASI}$, memegang peranan penting dalam upaya mempertahankan perilaku ibu untuk menyusui bayinya secara eksklusif karena ibu akan memiliki anggapan bahwa memberikan ASI adalah hal yang baik dan bermanfaat (24). Penelitian di Iran juga menunjukkan hasil yang sama yaitu petugas kesehatan memiliki peranan penting dalam mendorong dan mendukung ibu untuk tetap menyusui (25). Konseling ASI dilakukan sebagai upaya untuk menjaga kelangsungan pemberian ASI sehingga penting bagi 
petugas kesehatan untuk memiliki kemampuan dalam melaksanakan konseling ASI. Konseling ASI yang efektif mampu menyampaikan pesan kepada ibu menyusui dengan baik sehingga dapat membantu ibu untuk mengerti apa yang terbaik bagi ibu dan bayinya, memotivasi ibu untuk lebih percaya diri dan mampu menyusui secara eksklusif, serta ibu menyadari bahwa menyusui eksklusif merupakan dasar bagi kesehatan dan tumbuh kembang anak, selain untuk kesehatan ibu sendiri (26).

Keputusan ibu untuk memberikan ASI secara eksklusif kepada bayinya merupakan hal yang penting untuk terus diupayakan dan didukung. Rendahnya pemberian ASI eksklusif di keluarga menjadi salah satu pemicu rendahnya status gizi bayi dan balita. Memberikan ASI secara eksklusif adalah suatu cara yang sempurna dalam memberikan makanan yang ideal bagi pertumbuhan dan perkembangan bayi yang sehat serta mempunyai pengaruh biologis dan kejiwaan yang unik terhadap kesehatan ibu dan bayi (27). Hasil penelitian ini sesuai dengan penelitian sebelumnya yang dilakukan di Yogyakarta bahwa status pemberian ASI berpengaruh terhadap status gizi bayi usia 4-11 bulan dan bayi yang tidak mendapatkan ASI eksklusif memiliki risiko 3,898 kali lebih besar mengalami status gizi kurang dibandingkan dengan yang mendapatkan ASI eksklusif (28). Hasil penelitian tentang hubungan pemberian ASI eksklusif dengan tumbuh kembang pada anak di Puskesmas Karanganyar juga menunjukkan adanya hubungan yang bermakna antara pemberian ASI eksklusif dengan tumbuh kembang pada anak umur 3 sampai 6 bulan (29).

Berdasarkan hasil perhitungan persamaan regresi (variabel status pemberian ASI tidak eksklusif) dapat disimpulkan bahwa probabilitas atau tingkat risiko seorang bayi untuk mengalami gizi kurang jika status pemberian ASI tidak eksklusif adalah sebesar $25,54 \%$. Intervensi untuk peningkatan pemberian ASI eksklusif harus difokuskan terutama pada ibu karena ibu berisiko tinggi untuk tidak melanjutkan menyusui sejak dini saat bayi belum mencapai usia 6 bulan (30).

Analisis multivariat juga menunjukkan bahwa secara statistik tidak terdapat pengaruh yang bermakna antara tingkat pendidikan ibu terhadap status gizi. Hasil penelitian ini sejalan dengan penelitian di Tangerang Selatan yang menunjukkan bahwa pendidikan ibu tidak berhubungan bermakna dengan status gizi kurang pada anak. Pada dasarnya pendidikan ibu tidak berpengaruh langsung terhadap terjadinya gizi kurang. Keaktifan ibu untuk datang ke posyandu kemungkinan juga dapat mempengaruhi status gizi anaknya, baik secara langsung maupun tidak langsung. Seorang ibu dengan tingkat pendidikan yang tinggi sekalipun belum tentu memiliki pengetahuan yang cukup jika ibu tersebut jarang mendapatkan informasi mengenai gizi yang bisa diperoleh melalui media iklan, penyuluhan, dan sebagainya (31). Meskipun demikian, tingkat pendidikan ibu sangat berpengaruh terhadap kualitas dan kuantitas makanan yang dikonsumsi keluarga karena ibu memegang peranan penting dalam pengelolaan rumah tangga. Ibu yang berpendidikan tinggi mempunyai sikap yang positif terhadap gizi sehingga pada akhirnya akan semakin baik kuantitas dan kualitas gizi yang dikonsumsi keluarga yang termasuk di dalamnya adalah bayi dan balita (32).

\section{SIMPULAN DAN SARAN}

Status pemberian ASI berpengaruh bermakna terhadap status gizi bayi dan merupakan faktor risiko terhadap terjadinya gizi kurang pada bayi usia $6-12$ bulan di wilayah kerja UPTD Puskesmas Kalampangan Kota Palangka Raya, dengan probabilitas atau tingkat risiko seorang bayi untuk mengalami gizi kurang jika status pemberian ASI tidak eksklusif adalah sebesar $25,54 \%$.

Perlu peningkatan dukungan terhadap promosi pemberian ASI eksklusif yang dilaksanakan di tingkat puskesmas seperti konseling ASI, kelas ibu, dan promosi gerakan ASI eksklusif dengan penyediaan poster, leaflet, lembar balik, dan banner. Selain itu, perlu juga peningkatan monitoring berkala terhadap terjadinya gizi kurang pada bayi dan diseminasi informasi kepada masyarakat terutama ibu yang memiliki bayi bahwa pemberian ASI tidak secara eksklusif merupakan faktor risiko terhadap terjadinya gizi kurang.

\section{RUJUKAN}

1. Khomsan A, Wigna W. Aspek sosio-budaya gizi dan sistem pangan suku Baduy. Bogor: Fakultas Ekologi Manusia Institut Pertanian Bogor; 2009.

2. Sugiarti E. Faktor-faktor yang berhubungan dengan pemberian ASI eksklusif di Kecamatan Karangmalang Kabupaten Sragen [Skripsi]. Surakarta: Universitas Muhammadiyah Surakarta; 2011.

3. Inayati DA, Scherbaum V, Purwestri RC, Hormann E, Wirawan NN, Suryantan J, Hartono S, Bloem MA, Pangaribuan RV, Biesalski HK, Hoffmann V, Bellows AC. Infant feeding practices among mildly wasted children: a retrospective study on Nias Island, Indonesia. Int Breastfeed J 2012;7(1):3.

4. Afifah DN. Faktor yang berperan dalam kegagalan praktik pemberian ASI eksklusif [Tesis]. Semarang: Universitas Diponegoro; 2007.

5. Departemen Kesehatan RI. Manajemen laktasi. Jakarta: DEPKES RI; 2005.

6. Badan Penelitian dan Pengembangan Kesehatan RI. Riset kesehatan dasar (Riskesdas) 2010. Jakarta: Kementerian Kesehatan RI; 2010.

7. UPTD Puskesmas Kalampangan. Data cakupan program kesehatan tahun 2011. Palangka Raya: UPTD Puskesmas Kalampangan; 2011. 
8. Dinas Kesehatan Kota Palangka Raya. Data cakupan ASI eksklusif Kota Palangka Raya. Palangka Raya: Dinas Kesehatan Kota Palangka Raya; 2011.

9. WHO. Report of the expert consultation on the optimal duration of exclusive breastfeeding. Geneva, Switzerland: WHO; 2010.

10. Nadimin. Hubungan keluarga sadar gizi dengan status gizi balita di Kabupaten Talakar Sulawesi Selatan. Media Gizi Pangan 2010;10(2):1-7.

11. Hartati S. Pengaruh pemberian ASI eksklusif terhadap status gizi bayi usia 4-11 bulan di daerah perkotaan dan pedesaan Kabupaten Temanggung [Skripsi]. Semarang: Universitas Diponegoro; 2003.

12. Widyastuti E. Hubungan riwayat pemberian ASI eksklusif dengan status gizi bayi 6-12 bulan di Provinsi Nusa Tenggara Barat Tahun 2007 [Tesis]. Jakarta: Universitas Indonesia; 2009.

13. Roesli U. Mengenal ASI eksklusif. Jakarta: Niaga Swadaya; 2005.

14. Soekirman. Hidup sehat gizi seimbang dalam siklus kehidupan manusia. Jakarta: PT. Gramedia; 2006.

15. Nankunda J, Tumwine JK, Soltvedt A, Semiyaga N, Ndeezi G, Tylleskar T. Comunnity based peer counsellor for support of exclusive breastfeeding: experience from rural Uganda. Int Breastfeed J 2006;1:19.

16. Meikawati W, Hersoelistyorini W. Hubungan karakteristik ibu dan tingkat sosial ekonomi keluarga terhadap kasus gizi buruk pada balita di kelurahan Tandang Kecamatan Tembalang. Prosiding Seminar Nasional Hasil-hasil Penelitian [series online] 2008 [cited 2013 Feb 5];1(1):148-57. Available from: URL: http.//www. jurnal.unimus.ac.id

17. Linda O, Hamal DK. Hubungan pendidikan dan pekerjaan orang tua serta pola asuh dengan status gizi balita di Kota dan Kabupaten Tangerang, Banten. Prosiding Penelitian Bidang IImu Eksakta [series online] 2011 [cited 2013 Feb 5]. Available from: URL: http.//www.stkipislambumiayu.ac.id

18. Rahayu A. Karakteristik ibu yang memberikan ASI eksklusif terhadap status gizi bayi. Al 'ulum 2007;33(3):8-14.

19. Notoatmodjo SPD. Promosi kesehatan dan ilmu perilaku. Jakarta: Rineka Cipta; 2003.

20. Suhardjo. Perencanaan pangan dan gizi. Jakarta: Bumi Aksara; 2003.
21. Aidam BA, Perez-Escamilla R, Lartey A. Lactation counseling increases exclusive breast-feeding rates in Ghana. J Nutr 2005;135(7):1691-5.

22. Albernaz E, Victora CG, Haisma H, WrightA, Coward WA. Lactation counseling increases exclusive breast-feeding duration but not breast milk intake and measured by isotopic methods. J Nutr 2003;133(1):205-10.

23. Killewo J, Alam N, Gausia K, Ahmed F, Yunus Md, Chakraborty J, Persson LA. Determinant of exclusive breastfeeding in a rural area of Bangladesh. Malnutrition: meeting the challenges in South Asia programme and abstract of the $10^{\text {th }}$ Annual Scientific Conference of ICDDR; 2002 June 11-13; Dhaka.

24. Backstrom CA, Wahn El, Ekstrom AC. Two sides of breastfeeding support: experience of women and midwives. Int Breastfeed J 2010;5(20):1-8.

25. Olang B, Heidarzadeh A, Strandvik B, Yngve A. Reason given by mothers for discontinuing breastfeeding in Iran. Int Breastfeed J 2012;7(1):7.

26. WHO and UNICEF. Breastfeeding counselling: a training course. Geneva: WHO and UNICEF; 2000.

27. Rohani. Pengaruh karakteristik ibu menyusui terhadap pemberian ASI eksklusif di wilayah kerja Puskesmas Teluk Kecamatan Secanggang Kabupaten Langkat tahun 2007 [Skripsi]. Medan: Universitas Sumatera Utara; 2007.

28. Lastini ED. Pengaruh status pemberian ASI terhadap status gizi bayi usia 4-11 bulan di Kecamatan Kalibawang, Kulon Progo, Propinsi Daerah Istimewa Yogyakarta [Skripsi]. Semarang: Universitas Diponegoro; 2001.

29. Lidya NMS, Rodiah. Hubungan pemberian ASI eksklusif dengan tumbuh kembang pada anak usia 3 sampai 6 bulan di Puskesmas Karanganyar. Maternal 2011;5(5):154-67.

30. Tan KL. Factors associated with exclusive breastfeeding among infant under six months of age in Peninsular Malaysia. Int Breastfeed J 2011;6(1):1-7.

31. Syukriawati R. Faktor-faktor yang berhubungan dengan status gizi kurang pada anak usia 24-59 bulan di Kelurahan Pamulang Barat Kota Tangerang Selatan Tahun 2011 [Skripsi]. Jakarta: Universitas Islam Negeri Syarif Hidayatullah; 2011.

32. Khomsan A. Studi implementasi program gizi: pemanfaatan, cakupan keefektifan dan dampak terhadap status gizi. Bogor: Departemen Gizi Masyarakat Institut Pertanian Bogor; 2007. 